\title{
Corrosion of welds in biomass power plants
}

\author{
Montgomery, Melanie; Dahl, Kristian V.; Hald, John
}

Published in:

Materials and Corrosion

Link to article, DOI:

10.1002/maco.201810495

Publication date:

2019

Document Version

Peer reviewed version

Link back to DTU Orbit

Citation (APA):

Montgomery, M., Dahl, K. V., \& Hald, J. (2019). Corrosion of welds in biomass power plants. Materials and Corrosion, 70(4), 585-592. https://doi.org/10.1002/maco.201810495

\section{General rights}

Copyright and moral rights for the publications made accessible in the public portal are retained by the authors and/or other copyright owners and it is a condition of accessing publications that users recognise and abide by the legal requirements associated with these rights.

- Users may download and print one copy of any publication from the public portal for the purpose of private study or research.

- You may not further distribute the material or use it for any profit-making activity or commercial gain

- You may freely distribute the URL identifying the publication in the public portal

If you believe that this document breaches copyright please contact us providing details, and we will remove access to the work immediately and investigate your claim. 


\title{
Corrosion of Welds in Biomass Power Plants
}

\author{
Melanie Montgomery*, Kristian V. Dahl, John Hald \\ DTU Mechanical Engineering, Produktionstorvet - Building 425, DK 2800 Kgs. Lyngby, \\ Denmark \\ *Corresponding author: Melanie Montgomerymmon@mek.dtu.dk;
}

\begin{abstract}
In addition to understanding the corrosion of base materials in superheater tubes in biomass power plants, it is also important to understand how welded joints are subjected to corrosion or degradation. In the course of corrosion testing in the boiler, two different filler materials were used to weld together $18 \% \mathrm{Cr} 12 \% \mathrm{Ni}$ austenitic tubes. The two filler materials compared were a high alloyed Ni-based filler material (wt.\% approx. $20 \% \mathrm{Cr}, 12 \% \mathrm{Fe}, 3.6 \% \mathrm{Nb}$, Ti, balance $\mathrm{Ni}$ ) and the CN 18/11 IG filler material (18\%Cr, 10\%Ni, balance Fe). Austenitic steel test tubes were exposed in two different plants where the different filler materials were utilized and the attack of the welds and tubes adjacent the welds are described. Preferential attack of the tube material immediately adjacent the weld only occurred for the Ni rich weld and the indications are that this is galvanic corrosion. This type of attack decreased with decrease in steam temperature.
\end{abstract}

Keywords: biomass corrosion, Ni welds, $18 \% \mathrm{Cr}$ austenitic steel, selective attack, galvanic coupling

\section{Introduction}

The use of biomass as a fuel has increased over past decades as biomass is seen as a carbon dioxide neutral fuel. The Danish government has plans to reduce $\mathrm{CO}_{2}$ emissions by $80 \%$ by 2050, and as well as the use of wind turbines and other alternative fuel sources, the use of biomass in combined heat and power (CHP) boilers will contribute to this reduction. However, the combustion of straw/wood gives rise to certain corrosion problems that are not encountered with conventional coal combustion. Sulphur dioxide and potassium chloride are 
released when straw is combusted, and these compounds result in the deposition of potassium chloride and potassium sulphate on the vulnerable superheater components.

A great deal of laboratory research has been undertaken into corrosion in biomass plants. The corrosion research has consisted of laboratory experiments looking at the role of the deposit e.g. [1], the initial attack of chromia formers e.g. [2], assessment of materials which are chromia formers $[3,4]$ and silica and alumina formers $[5,6,7]$. These studies have shown that a protective oxide of chromium cannot be formed when potassium chloride is present. More complex corrosion studies have also been undertaken exposing austenitic stainless steel to simulated flue gas and deposits $[8,9,10,11]$ such that an improved understanding of how specific components of the flue gas (water vapour and $\mathrm{SO}_{2}$ ) can influence corrosion.

In addition, plant corrosion testing and also failure assessment in biomass power plants has given information with respect to alloy selection and corrosion rates at various temperatures $[12,13,14]$. This has resulted in the use of lean austenitic steels such as TP347H and the recommendation that the steam outlet temperature be limited to $540^{\circ} \mathrm{C}$. Methods to reduce corrosion either by co-firing with fossil fuels or use of additives have also been investigated in the plant $[12,15]$.

In addition to understanding the corrosion of base materials, it is also important to understand how different welded joints can be subjected to corrosion. Although in general, welding would be preferred in the penthouse area, it is unavoidable within the superheater loop, both during construction and especially if there has been a failure and repair is undertaken. However the assessment of welds has not been so extensive and poor understanding of the corrosion mechanism could lead to incorrect material choices (filler materials) and potentially to failures.

A previous investigation from our group on a test superheater exposed in a biomass plant revealed results pointing to galvanic corrosion of tubes adjacent welds using nickel based 
filler material (Nibas) [16]. The test superheater loop was exposed for only 3500 hours and both Nibas filler and CN 18/11 IG filler material (composition similar to the austenitic steels that were welded) were utilized. Cross-sections of some of the investigated welds are shown in Figure 1. The CN 18/11 IG weld showed no increased corrosion at the tube-weld transition zone (Figure 1a), however this was observed on a Nibas weld just $10 \mathrm{~cm}$ away and therefore exposed to similar operation parameters (Figure $1 \mathrm{~b}$ ). The severity of corrosion attack of the tube adjacent the Nibas weld decreased as the steam temperature decreased such that at an estimated steam temperature of $514^{\circ} \mathrm{C}$, it was no longer observed (Figure 1c).

In aqueous corrosion, the problems of galvanic corrosion are well-known where the less alloyed anode is corroded preferentially when it is adjacent the more noble cathode. In high temperature corrosion there is also the possibility of a type of galvanic corrosion due to molten salts acting as the electrolyte. Kawahara et al. [17] described localised corrosion of a carbon steel tube (SA178) adjacent a 625 alloy in a waste incineration plant, and how this effect could only be reproduced in the laboratory with a simulated flue gas and molten salts containing heavy metal chlorides, when there was a thermal gradient between the gas and the corroding metal. Reid [18] has suggested that in coal-firing systems where there is varying temperature around the circumference of a tube, a macrogalvanic couple can exist on a tube resulting in greater corrosion on the areas of metal covered with molten sulphates, which would be more anodic than adjacent areas beneath solid deposits. In a biomass power plant, the electrolyte could consist of molten salts, e.g. mixtures of potassium chloride and iron chloride have a lowest melting point of $374^{\circ} \mathrm{C}$ [19] or $\mathrm{KCl}$ and chromium chloride mixtures that have a lowest melting point of $462^{\circ} \mathrm{C}$ [20]. Laboratory experiments with TP347H have indicated that iron chloride evaporates from the corrosion front and can form a melt together with potassium chloride and potassium sulphate at $560^{\circ} \mathrm{C}[10]$. 
The results from Figure 1 were from a test loop with high steam temperatures located in the first pass thus also subjected to high flue gas temperatures and could have resulted in the presence of molten salts leading to this type of attack. Usually superheaters with a high steam temperature are located where there are lower flue gas temperatures. This paper describes in detail the in-plant behaviour of two different weld filler materials exposed in the actual superheaters of two different boilers for longer exposure times (up to 30000 hours) and compares the findings with previous observations from the test superheater [16].

\section{Materials and Methods}

In the course of corrosion testing, two different filler materials were used to weld austenitic tubes which were then built into the actual superheaters of two different plants, Plant A and Plant B. There are two weld types compared in this paper, a weld using CN 18/11 IG filler material utilized in Plant A, which has a similar composition to the austenitic steel tubes, and a weld using a high nickel alloyed filler material from Plant B.

The approximate composition of the filler materials and the tubes adjacent the welds are given in Table 1. Composition analysis of the weld B was undertaken in the area where there is assumed to be lowest level of dilution, i.e. top centre of the weld closest to the flue gas. The welds investigated were $\mathrm{V}$ type welds where the greatest dilution was observed on the steamside of the tube. For both weld filler materials, the adjacent tubes were an $18 \% \mathrm{Cr}$ 12\%Ni type steel, TP347H. The composition of the Nibas weld studied in [16] is also given as the results are referred to in this paper.

Plant A was a grate-fired boiler with mainly straw combustion and Plant B was a suspension fired boiler where straw and wood pellets were used. The temperature of the steam from the superheaters to the turbine was $540^{\circ} \mathrm{C}$ for both boilers; however, there were differences of the actual tubes due to varying heat flux in tube bundles. Two weld-tube 
sections are compared from Plant $\mathrm{B}$, one close to the outlet with a steam temperature of approx. $536^{\circ} \mathrm{C}$ and one close to the inlet with a steam temperature of $499^{\circ} \mathrm{C}$. The tube section investigation from plant A had a estimated steam temperature of $554^{\circ} \mathrm{C}$. The actual metal temperature can be $20-30^{\circ} \mathrm{C}$ higher depending on the heat flux.

Tube sections were cut from the superheaters, and were prepared using normal metallographic techniques but without the use of water: instead absolute alcohol was used as a lubricant to preserve water soluble species in the corrosion product. The specimens were investigated with light optical and scanning electron microscopy with EDS analysis (JEOL 5900 equipped with Oxford Instruments EDS). The images of cross-sections presented in this paper are produced using the back-scattered (BSE) detector such that elements with a higher atomic number such as niobium appear brighter. In addition deposits adjacent the tube were analysed for plant B, where the deposit was removed from the tube surface with a scalpel, carbon coated and analysed with SEM. The surface of the deposit is analysed in secondary ion mode to reveal the morphology of the deposit and corrosion products.

\section{Results}

For both plants, there were similarities of the corrosion attack of the $18 \% \mathrm{Cr}$ austenitic tubes. However, the attack of the welds and the tube area adjacent the weld were different as will be shown in the following sections. The exposure time, estimated steam temperature and corrosion rates for $\mathrm{TP} 347 \mathrm{H}$ tubes away from welds is given in Table 2, where plant A was running at a higher temperature than plant $\mathrm{B}$ and therefore had a higher corrosion rate.

Over the years, many tubes have been investigated and the typical morphology of the attack for an $18 \% \mathrm{Cr} 12 \% \mathrm{Ni}$ steel $(\mathrm{TP} 347 \mathrm{H})$ is shown in Figure 2 revealing grain boundary 
attack at the corrosion front and selective attack above this. Figure 2 is from the tube from Plant B but approximately $10 \mathrm{~cm}$ from a weld, and a similar morphology has been seen for tubes from many different power plants in Denmark [12] including Plant A. Within the inner part of the corrosion product, selective attack was evident where Cr depletion was observed. Towards the surface of the tube, porous chromium and iron oxide layers were present. Metallic nickel was present within this oxide as isolated particles.

\subsection{Deposit analysis and attack of the tube}

Analysis of deposits on the tubes from both plants revealed the presence of potassium chloride and potassium sulphate adjacent the oxide. The deposit in Figure 3a was from the higher steam temperature $\left(536^{\circ} \mathrm{C}\right)$ whilst the deposit in Figure $3 b$ and $3 c$ were from the lower steam temperature section. The presence of compounds containing calcium, magnesium and silicon was more prevalent for Plant B (Figure 3a). Figure 3b and 3c shows the underside of the deposit/corrosion product (which was adjacent the tube) where $\mathrm{K}, \mathrm{Cl}$ and Fe are major components of a phase with a molten appearance (analysis A, E and F). Another morphology was rich in $\mathrm{Cr}, \mathrm{O}$ and $\mathrm{Fe}(\mathrm{C}$ and $\mathrm{D})$, whereas analysis $\mathrm{B}$ is an iron rich oxide. The surface of the corrosion product is uneven and there are presumably different phases on top of each other, so the EDX analyses probably include elements from underlying phases and should be only used as an indication of possible compounds. In addition, since hydrogen and carbon cannot be analysed, the presence of carbonates or hydroxide can neither be confirmed nor dismissed.

\subsection{CN 18/11 IG weld from plant A}

Figure 4 shows the attack on the CN 18/11 IG weld after 17000 hours exposure in Plant A at $554^{\circ} \mathrm{C}$. On the tube side, there is grain boundary attack and a similar morphology to Figure 
2. On the weld side there is preferential interdendritic attack (not shown). There is no increased corrosion attack on either the weld, tube or the transition zone. The corrosion attack of the weld and tube is similar in that there is attack along the interdendritic zone or grain boundaries at the corrosion front, and these function as pathways allowing ingress of corrosive species. The outer oxide is a mix of iron and chromium rich oxide with islands of metallic nickel.

\subsection{Ni weld from plant $B$}

Figure 5 shows the attack for the tube adjacent the nickel weld after 30000 hours exposure in plant $\mathrm{B}$ at a temperature of $536^{\circ} \mathrm{C}$. Similar to the weld from Plant $\mathrm{A}$, the attack at the corrosion front for the weld seems to be within the interdendritic phase. However, there is significant corrosion attack of the austenitic tube adjacent the Ni weld which decreases with distance from the weld. This is similar to that observed for [16]. The corrosion rate for the tubes in Plant B is lower than that for Plant A probably due to the lower temperature (Table 2), so the increased corrosion near the weld is not due to more severe operation parameters.

Closer analysis of the area adjacent the weld at the corrosion front shows the presence of a layered structure of Fe-Cr oxide and Fe-Ni oxide and not the typical grain boundary attack (Figure 6). There is also a measurable trace of chlorine within this area, but no traces of potassium. The $\mathrm{Cl}$ levels shown in the mapping is background and a maximum $\mathrm{Cl}$ content of $1 \mathrm{wt}$ \% was measured close to the corrosion front. Nickel is still present as metallic nickel in islands between the corrosion products but is also present as Fe-Ni oxide.

A specimen taken closer to the inlet with an estimated lower steam temperature of $499^{\circ} \mathrm{C}$ was also investigated and the regions adjacent the weld are compared in Figure 7 . The colder weld reveals limited preferential attack of the tube adjacent the weld, which is only localized 
to the outer area closest to the surface, and then grain boundary attack is observed similar to the rest of the tube (compare with Figure 2).

From the observations it can be concluded that: a) localised increased corrosion occurs only for tube sections adjacent high Ni containing welds and b) the corrosion attack is more severe with increasing temperatures.

\section{Discussion}

For $18 \% \mathrm{Cr}$ austenitic steel superheater tubes, grain boundary attack was seen as a precursor to selective corrosion of chromium and iron [12]. The deposited potassium chloride reacts with oxides or sulphur dioxide resulting in release of chlorine species which migrate to the corrosion front. These $\mathrm{Cl}$ species react with the alloy - chromium first as this has the greatest affinity for chlorine. The metal chlorides formed are volatile and therefore evaporate from the corrosion front and when they reach an area of higher oxygen partial pressure, they are oxidised, releasing chlorine and forming non-protective oxides [3,4].

With respect to the tube areas adjacent welds, another corrosion mechanism is also contributing to the gas phase corrosion attack observed on the tubes. Even though the tube from plant B had acceptable corrosion rates, there was higher corrosion attack around the welds and this was not observed for plant A. This attack only occurs when Ni rich filler material is used to weld $18 \% \mathrm{Cr}$ type austenitic steels and increases in extent with increase in temperature. This was previously observed for the Nibas weld quality [16] and is also the case for the $61 \% \mathrm{Ni}, 21 \% \mathrm{Cr}, 12 \%$ Fe weld used in Plant B and described in this paper. Based on the results presented it is suggested that the mechanism of attack is high temperature galvanic corrosion. If two alloys with different corrosion potentials are located adjacent one another and connected by an electrolyte, galvanic corrosion is likely to occur. In this paper, 
corrosion of the TP347H steel tube is more severe in the region adjacent the high nickel containing weld. Such severe localised corrosion was not observed for the TP347H tubes adjacent welds of filler material with a composition similar to the tubes although they were exposed in a plant with higher corrosion rates. If the galvanic series for various alloys in seawater is consulted [21], and for comparison purposes the nickel filler utilised has a composition close to alloy 600: the active 347 stainless steel is more anodic than active alloy 600 indicating that the nickel rich weld could act as the cathode and the stainless steel tube (TP347H) as the anode.

To have galvanic corrosion, an electrolyte has to connect two dissimilar alloys. The exact composition of such an electrolyte has not been identified, but the presence of a molten phase on the underside of the deposit is observed that is rich in $\mathrm{K}, \mathrm{Cl}$ and $\mathrm{Fe}$ (Figure 3). Thus $\mathrm{KCl}$ together with iron chloride [19] could form a melt phase. Indications of formation of a $\mathrm{FeCl}_{2^{-}}$ $\mathrm{KCl}$ melt were also revealed with top-down SEM analysis of corrosion products/deposits from laboratory exposures [10]. At the anode, the reaction will be the oxidation reaction: $\mathrm{M}$ $\rightarrow \mathrm{M}^{\mathrm{n}+}+\mathrm{n} e^{-}$, metal oxidized to cations + electrons which would travel through the cathode, however the reaction at the cathode is more complicated. Nishikata et al [22] investigated with polarization measurements the presence of oxidizing agents like water vapour and oxygen in $\mathrm{KCl}-\mathrm{NaCl}$ salts at $700^{\circ} \mathrm{C}$ and showed how $\mathrm{OH}^{-}$or $\mathrm{O}^{2-}$ ions can occur resulting in higher corrosion rates. As outlined in ref [23], due to the incoming oxidizing species, removal of corrosion product and thermal gradient, the corrosion deposit is always in contact with incoming oxidizing species, so the molten deposit will continue to be replenished in oxidizing species resulting in cathodic reactions at the weld surface.

However, the corrosion front at the pit at the weld-tube is further away from the surface and the deposits, therefore $\mathrm{KCl}$ is no longer likely to be a part of the electrolyte, and potassium is not detected in this area. Here the electrolyte could be a mixture of different 
metal chlorides, i.e. iron chloride, chromium chloride and nickel chloride: the melting points of relevant metal chlorides are given in Table 3. In fact a nickel-oxygen-chloride phase has been identified close to the corrosion front for laboratory exposed specimens [25]. Investigations of waterwall specimens identified iron chloride only when FIB specimens were analysed with SEM-EDS without being removed from the high vacuum equipment, otherwise iron-oxygen-chlorine was detected in cross-sectioned specimens; the conclusion was that the metal chloride is oxidized when it comes into contact with the air during preparation [26]. This could also have occurred for the analysis in [25]. Therefore more sophisticated characterization methods are needed to discover the exact composition of the electrolyte at the corrosion front. Oxidising species will be in the outer part of the pit away from the corrosion front and oxidise the chlorides.

Comparing the morphology in Figure 2a and Figure 6, it is clear that nickel has reacted to form corrosion products on the tube adjacent the weld but not away from the weld. In a galvanic couple, there will be a shift in potential of the anode and thus elements which were inert can become active. This can explain that nickel is reactive in the anodic tube adjacent the cathodic weld. The shift in electrode potential will also affect chromium and iron potentially increasing the localized attack. The layered structure of $\mathrm{Cr}$ and $\mathrm{Fe}$ and $\mathrm{Ni}$ corrosion product can be explained based on the work of Abramov et al [27] who conducted experiments for stainless steel in inert chloride melts and measured the presence of metallic chloride ions (e.g. $\mathrm{NiCl}_{4}{ }^{2-}, \mathrm{CrCl}_{4}{ }^{2-}, \mathrm{FeCl}_{4}{ }^{2-}$ ) with in situ electronic absorption spectroscopy. Fe and Cr chloride ions were usually detected initially, however if the steels had been previously heat treated, nickel chloride ions were first detected, due to $\mathrm{Cr}$ being depleted from the surface. For the weld shown in Figure 6, it is suggested that the more electronegative components in the steel such as Fe and Cr react first, and then a Ni rich layer is left resulting in Ni reaction, and then the Fe and $\mathrm{Cr}$ are again preferentially attacked. In this 
paper only traces of chlorine (about 1 wt.\%) were present together with iron, oxygen, and nickel at the corrosion front, however chlorine has been observed within the "pit" in our earlier paper [16]. As the corrosion front moves inwards, the metallic chlorides are converted to oxides. Both iron and chromium chloride are more volatile than nickel chloride and would be continually removed from an electrolyte especially with the thermal gradient present around the superheater tubes and this would also affect the observed corrosion products. What would remain is an electrolyte rich in nickel chloride which would be continually replenished with iron chloride because of iron's abundance in the TP347H tube. The exact mechanism is difficult to elucidate because of the different parameters in the boiler, but the fact that Kawahara et al [17] only observed galvanic corrosion in the laboratory in the presence of a thermal gradient suggests that this also has an influence and a thermal gradient is always present in the boiler. The tubes from the test superheater [16] had both high steamside and flue gas temperatures and therefore a higher surface metal temperature than in plant $\mathrm{B}$, and in addition from comparing weld composition, Nibas would be more cathodic that the plant B weld filler material. Therefore this corrosion mechanism resulted in failure after only 3500 hours.

Previous laboratory work [28] has suggested that electrochemical reactions occur with Cl and $\mathrm{O}$ anions being adsorbed on the surface and transported via grain boundaries to the corrosion front. A similar reaction is indicated here which is driven by the presence of a galvanic couple and the greater the percentage of melt phase in the corrosion product, i.e. at higher temperatures, the greater the corrosion attack. At the lower steam temperature of $499^{\circ} \mathrm{C}$, a smaller proportion of the corrosion products will be molten and the gas phase reactions producing the metal chlorides are slower, thus the only molten phase is at the surface involving $\mathrm{KCl}$ and iron chloride resulting in limited attack of the 18Cr12Ni anode. The observations from previous work [16] that the corrosion rate for the tube adjacent the 
weld decreases with decreasing temperature (Figure 1) is probably due to the fact that the conductivity of the electrolyte falls since the amount of molten phase within the electrolyte decreases.

The nobility of the weld will also depend on the dilution of the weld metal during welding. For the Ni weld from plant B, the iron content of the weld at the steamside was $20-30$ wt.\% and decreased to $10 \%$ at the top centre of the weld. Therefore the weld composition adjacent the tube can vary (Figure 5) as the location of the corrosion front moves during exposure which would result in a lower shift in electrode potential and therefore less galvanic corrosion as the weld material further down is less cathodic. In contrast the composition of the weld becomes more noble during exposure as iron and chromium are being preferentially attacked leaving more nickel rich alloy and therefore a greater shift in potential encouraging the galvanic corrosion of the adjacent tube.

\section{Conclusions}

The corrosion of tubes from different biomass plants was compared in order to assess the use of different weld filler materials. The following conclusions can be drawn:

- Increased corrosion of the $18 \% \mathrm{Cr}$ austenitic tube was only observed when the tube was adjacent a high nickel containing weld and the degree of attack decreased with distance from the weld. No increase in corrosion was observed when the filler material had a composition similar to the tube.

- The increased corrosion is highly temperature dependent and was less obvious when the estimated steam temperature was below $499^{\circ} \mathrm{C}$. 
- It is suggested that galvanic corrosion can occur in biomass plants where the electrolyte is KCl deposit products and/or metal chlorides. This will be more severe at higher metal or flue gas temperatures.

- The use of more noble weld filler material compared to the tube should be avoided within the combustion zone where molten compounds could be present.

\section{Acknowledgements}

This paper was written under the FORSKEL project "Biomass Corrosion Management" with financial support from Energinet.dk and Ørsted. 


\section{REFERENCES}

1. J. Lehmusto, B.J. Skrifvars, P. Yrjas, M. Hupa M, Fuel Process Technology. 2013, 105, 98.

2. K. Segerdahl, J. Petterson, J.E. Svensson, L.G. Johansson, Material Science Forum. 2004, 461-464, 109.

3. S. Kiamehr, K.V. Dahl, M. Montgomery, M.A.J. Somers, Materials and Corrosion 2015, 66,1414 .

4. D.L. Singbeil, L. Frederick, J.R. Keiser, W.B.A Sharp, TAPPI PEERS Conference 2013 1088.

5. S. Kiamehr, K.V. Dahl, M. Montgomery, M.A.J. Somers Materials and Corrosion, 2016, 67, 26.

6. Y.S. Li, Y. Niu, M. Spiegel, Corrosion Science. 2007, 49, 1799.

7. N. Israelsson, K.A. Unocic, K. Hellström, J.E. Svensson, L.G. Johansson, Oxid. Met. 2015 84, 269.

8. J. Pettersson, J.E. Svensson, L.G. Johansson Materials Science Forum, 2008, 595-598, 367.

9. S. van Lith, F.J. Frandsen, M. Montgomery, T. Vilhelmsen, S.A. Jensen, Energy and Fuels 2009, 23, 3457.

10. S. Okoro, F.J. Frandsen, M. Montgomery, K. Pantleon Energy and Fuels. 2014, 29, 5802.

11. M. Paneru, G. Stein Brzozowska, J. Maier, G. Scheffknecht, Energy \& Fuels, 2013 27, 5699.

12. O.H. Larsen, M. Montgomery, Energy Materials. 2006, 1, 579.

13. M. Montgomery, S.A. Jensen, U. Borg, O. Biede, T. Vilhelmsen, Materials and Corrosion. 2011, 62, 593.

14. J.R. Keiser, W.B.A. Sharp, D.L. Singbeil, TAPPI PEERS Conference 2013, 1107.

15. P. Henderson, P. Szakalos, R. Pettersson, C. Andersson, J. Högberg, Materials and Corrosion. 200657128.

16. M. Montgomery, B. Carlsen, O. Biede, O.H. Larsen, Proceedings NACE Corrosion Conference March 2002, Paper 02379.

17. Y. Kawahara, M. Kira, M. Ike Proceedings Symposium High Temp. Corrosion \& Protection. Science Reviews 2000 pp 627- 634.

18. W.T. Reid, External corrosion and deposits: boilers and gas turbines. p.122, Elsevier New York 1971.

19. E.M. Levins, C.R. Robbins, H.F. McMurdies "Phase diagrams for Ceramists" 1969 supplement (Figure 3057) American Ceramic Society, Columbus Ohio 1969.

20. G. Smith, M.A. Clevinger, R.S. Roth, LP Cook "Phase diagram for Ceramists (Figure 5646) American Ceramic Society, Columbus Ohio 1983.

21. R. Baboian “Corrosion: Fundamentals, Testing and Protection" Vol 13A, ASM Handbook, p 210 ASM International, 2003.

22. A. Nishikata, H. Numata, T. Tsuru, Materials Science and Engineering, 1991, A146, 15.

23. D. Inman, G. Picard, "Corrosion in Fused Salts" in Corrosion: Third Edition - 2013, Volume 2, pp. 130-142, Publisher Elsevier.

24. G.Y. Lai "High Temperature Corrosion and Materials Applications" p151, ASM International 2007.

25. S. Okoro, M. Montgomery, F.J. Frandsen, K. Pantleon, Materials at High Temperatures. 2015, 32, 92.

26. Y. Alipour, P. Henderson, P. Szakalos, Materials at High Temperature. 2015, 32, 188. 
27. A.V. Abramov, I.B. Polovov, V.A. Volkovich, O.I. Rebrin, Molten Salts Chemistry and Technology p. 427, John Wiley and Sons Ltd, Chichester UK, 2014.

28. N. Folkeson, L.G. Johansson, J.E. Svensson: J. Electrochemical Society 2007, 154, C515. 


\section{FIGURES}

Figure 1. Attack of $18 \%$ Cr stainless steel tubes adjacent welds for different filler materials and different estimated steam temperatures. Figure $1 \mathrm{~b}$ shows preferential attack of the tube immediately adjacent the Nibas weld.

Figure 2: Typical corrosion attack of TP347H austenitic steel tubes located far from welds at steam temperature $540^{\circ} \mathrm{C}$ from Plant B.

Figure 3: Morphology and analysis of deposit underside (Fig 3c) removed from tube from Plant B.

Figure 4. Attack of 18\% Cr stainless steel tubes adjacent the CN 18/11 IG weld. Estimated steam temperature $554^{\circ} \mathrm{C}$.

Figure 5. Attack of $18 \%$ Cr steel tube (on the left) adjacent the Ni weld (right). Estimated steam temperature $536^{\circ} \mathrm{C}$.

Figure 6. Attack of TP347H stainless steel tubes (right) adjacent Ni weld (left) at the corrosion front. Estimated steam temperature $536^{\circ} \mathrm{C}$.

Figure 7: Weld-tube section from superheater in plant B showing effect of temperature.

\section{TABLES}

Table 1. Compositions for materials investigated in wt.\%.

Table 2. Comparison of plant data for welds investigated

Table 3. Melting points of various metal chlorides [24] 


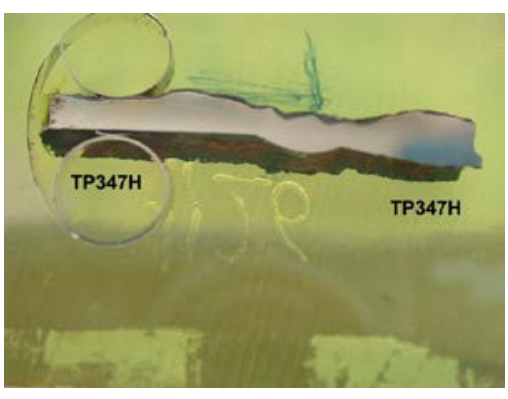

a) $\mathrm{CN} 18 / 11 \mathrm{IG}, 568^{\circ} \mathrm{C}$

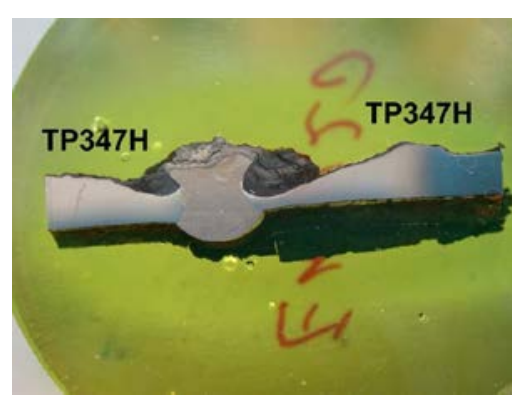

b) Nibas, $570^{\circ} \mathrm{C}$

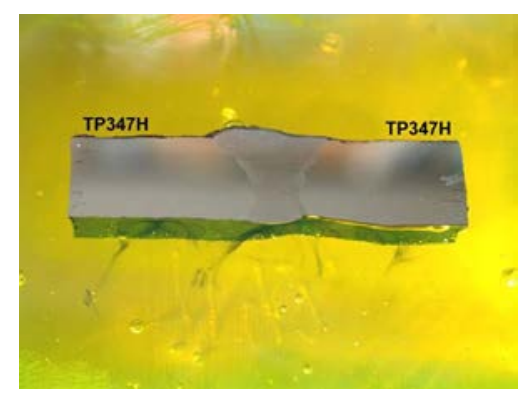

c) Nibas, $514^{\circ} \mathrm{C}$

Figure 1. Attack of $18 \%$ Cr stainless steel tubes adjacent welds for different filler materials and different estimated steam temperatures. Figure 1b shows preferential attack of the tube immediately adjacent the Nibas weld.

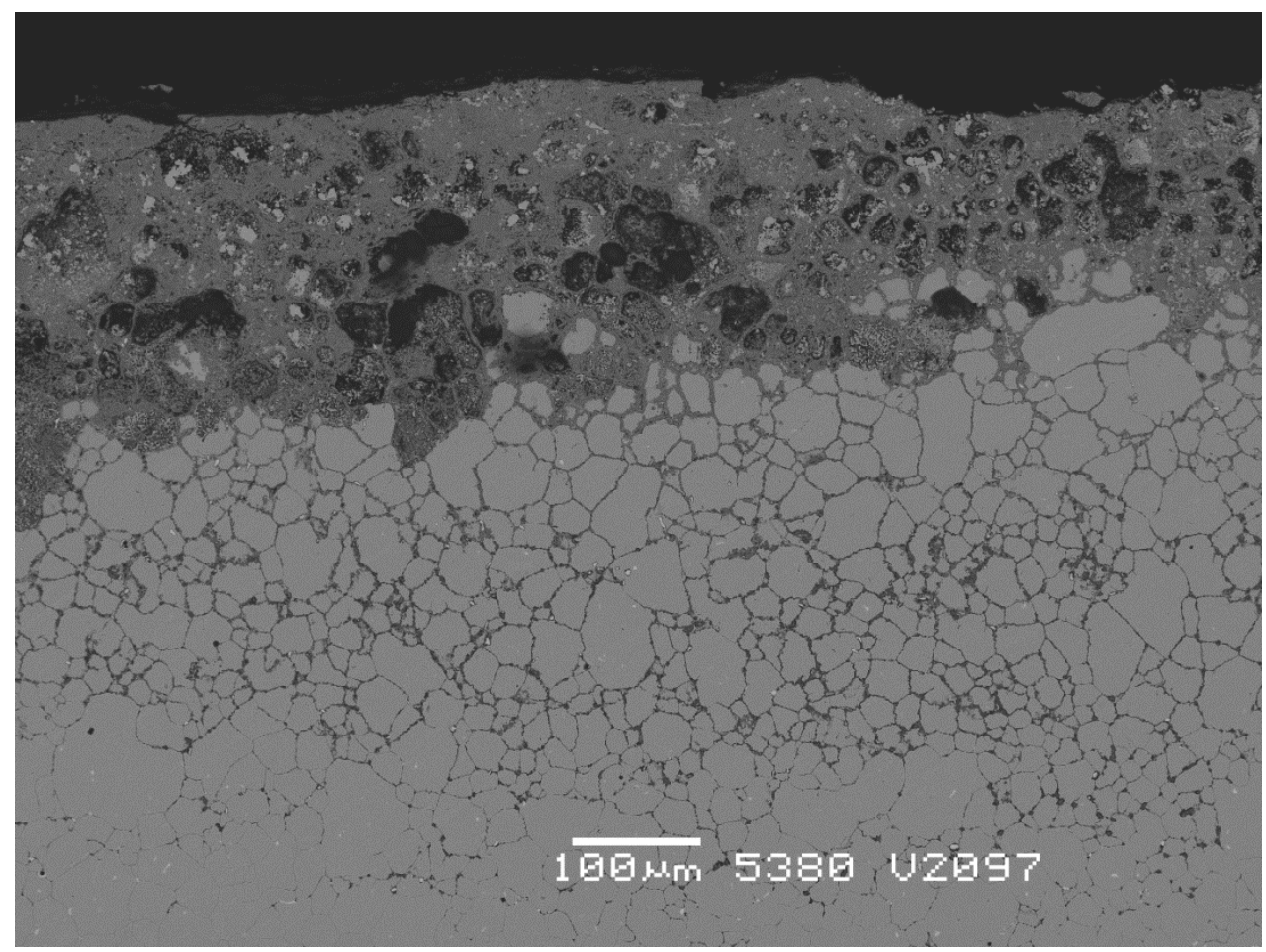

Figure 2: Typical corrosion attack of TP347H austenitic steel tubes located far from welds at steam temperature $540^{\circ} \mathrm{C}$ from Plant B. 


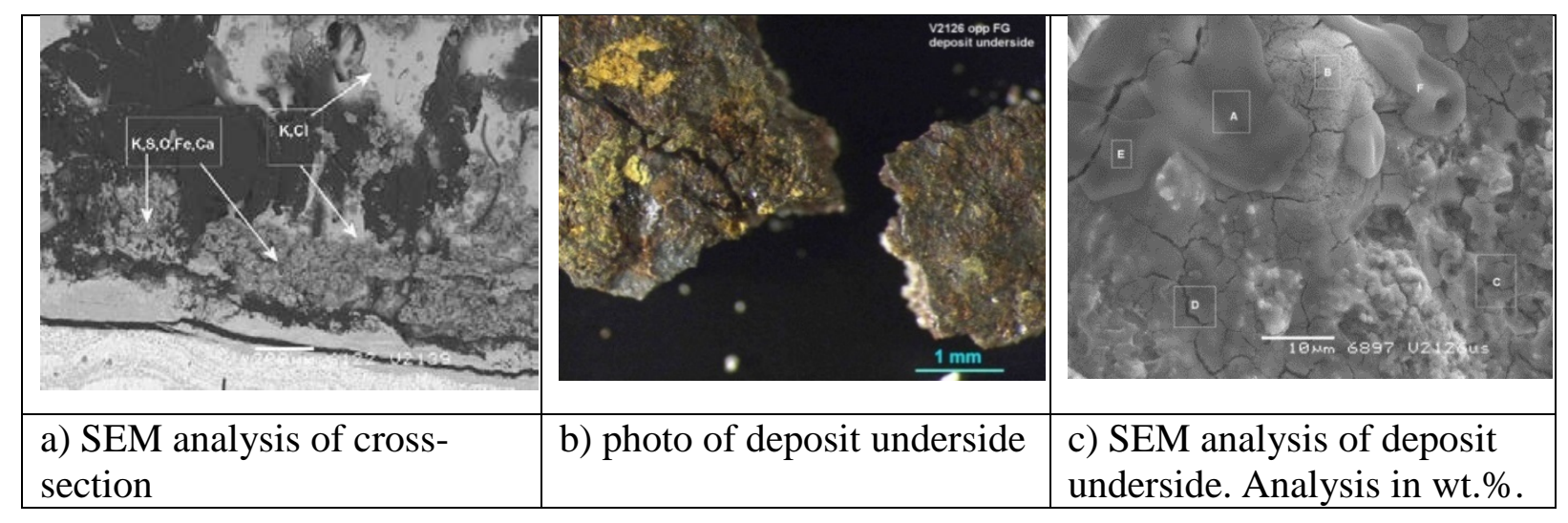

\begin{tabular}{lcccccccccc}
\hline Figure 3c & $\mathbf{O}$ & Si & S & Cl & K & Cr & Mn & Fe & Ni & Nb \\
\hline A & 2 & & & 25 & 28 & 5 & 1 & 32 & 7 & \\
B & 41 & & 1 & 1 & 3 & 6 & 1 & 37 & 9 & \\
C & 26 & $<1$ & $<1$ & 2 & 2 & 26 & 1 & 35 & 6 & 1 \\
D & 32 & $<1$ & $<1$ & 2 & 3 & 16 & 1 & 35 & 11 & \\
E & 2 & & $<1$ & 25 & 49 & 7 & 1 & 15 & 1 & \\
F & 18 & & $<1$ & 22 & 22 & 3 & 1 & 29 & 5 & \\
\hline
\end{tabular}

Figure 3: Morphology and analysis of deposit underside (Fig 3c) removed from tube from Plant B. 

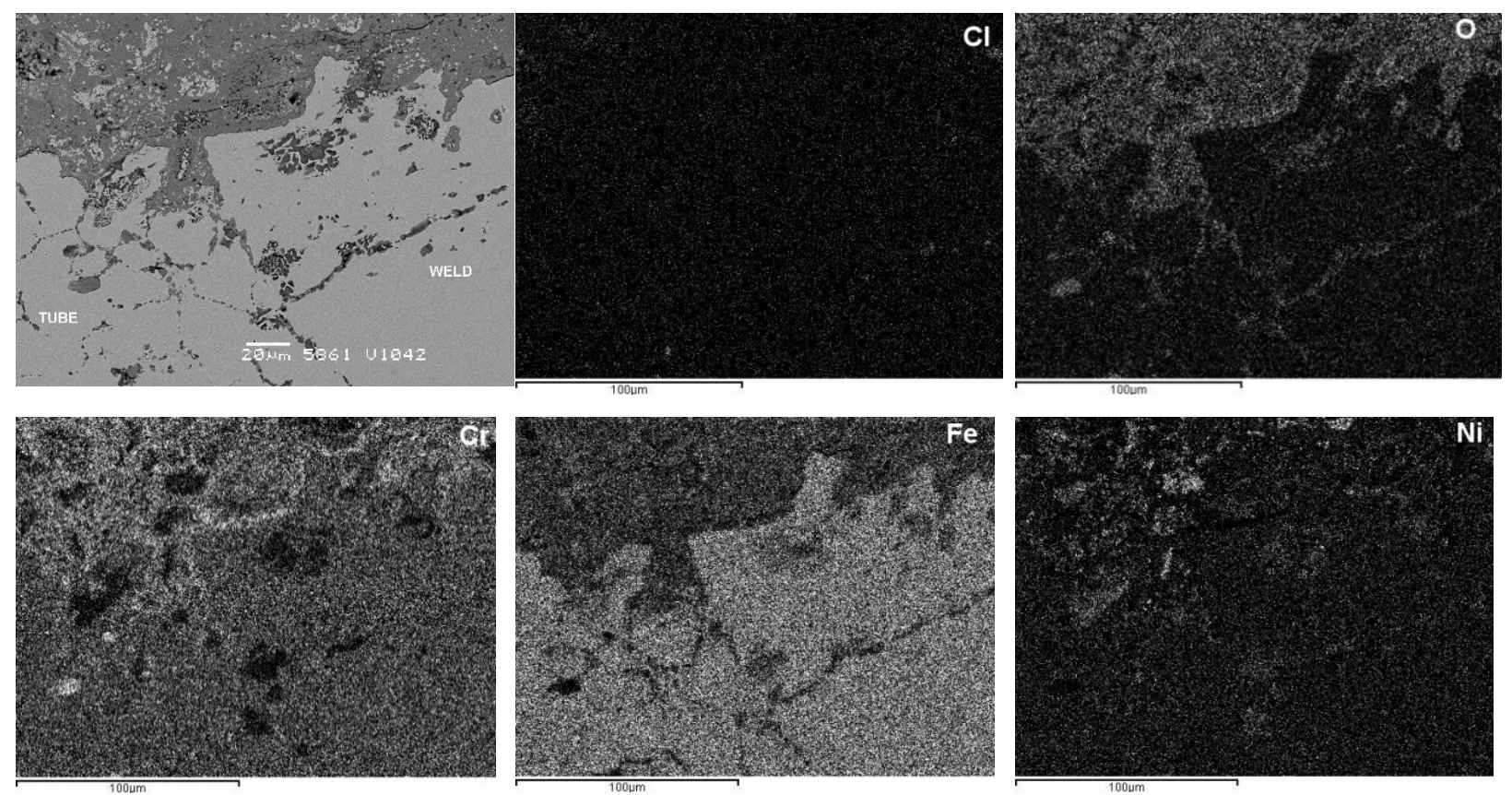

Figure 4. Attack of 18\% Cr stainless steel tubes adjacent the CN 18/11 IG weld. Estimated steam temperature $554^{\circ} \mathrm{C}$. 

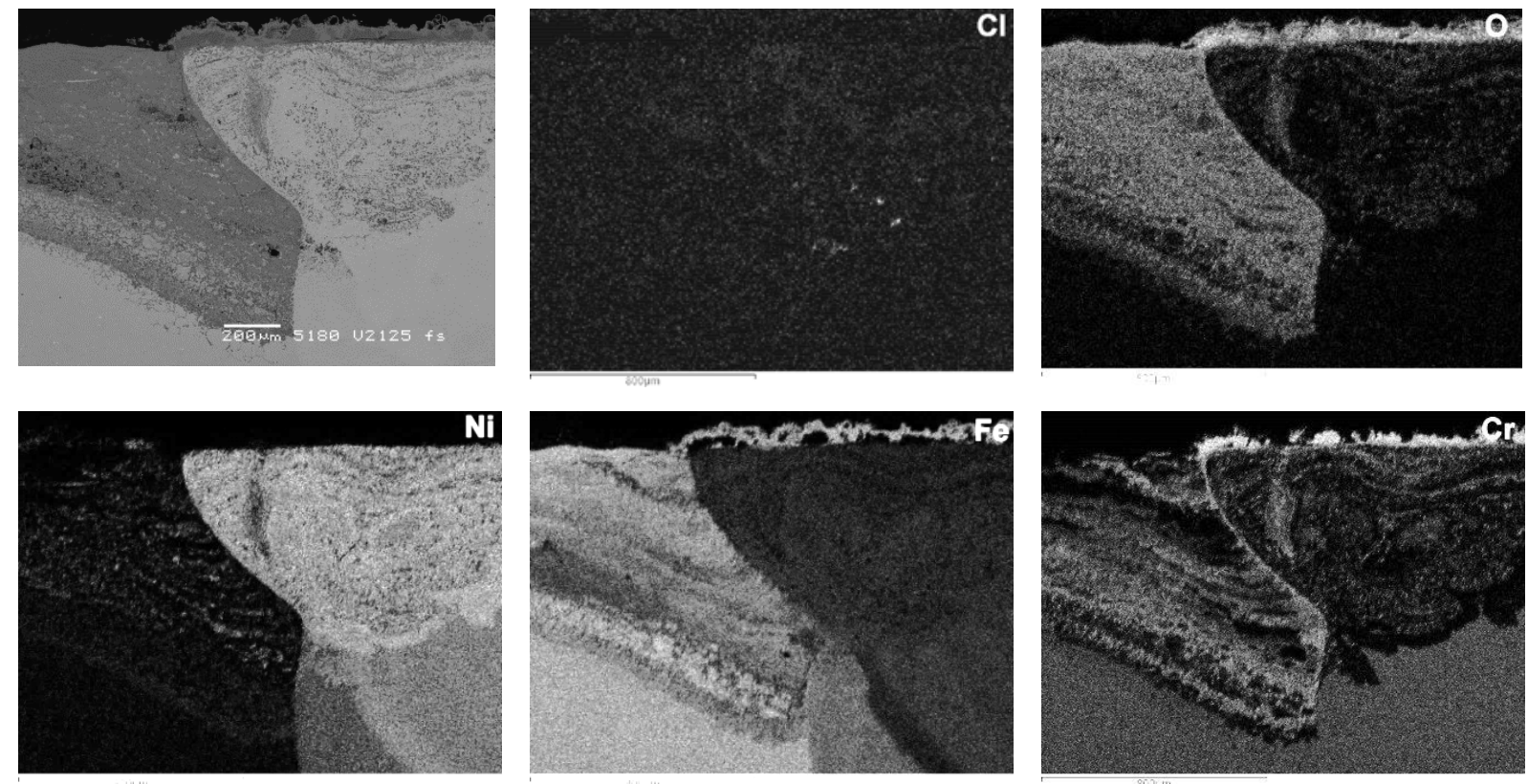

Figure 5. Attack of $18 \%$ Cr steel tube (on the left) adjacent the Ni weld (right). Estimated steam temperature $536^{\circ} \mathrm{C}$. 

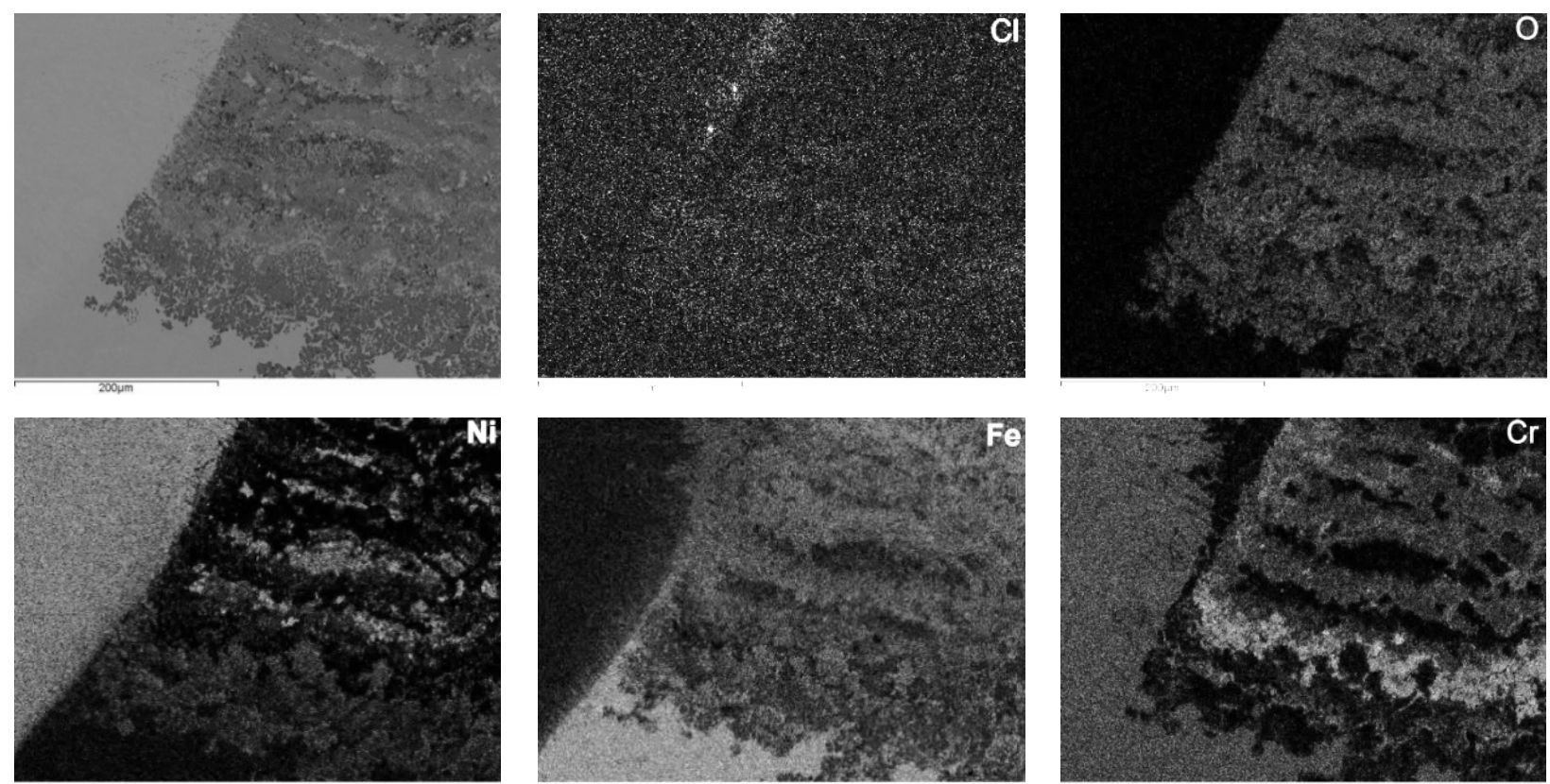

Figure 6. Attack of TP347H stainless steel tubes (right) adjacent Ni weld (left) at the corrosion front. Estimated steam temperature $536^{\circ} \mathrm{C}$. 


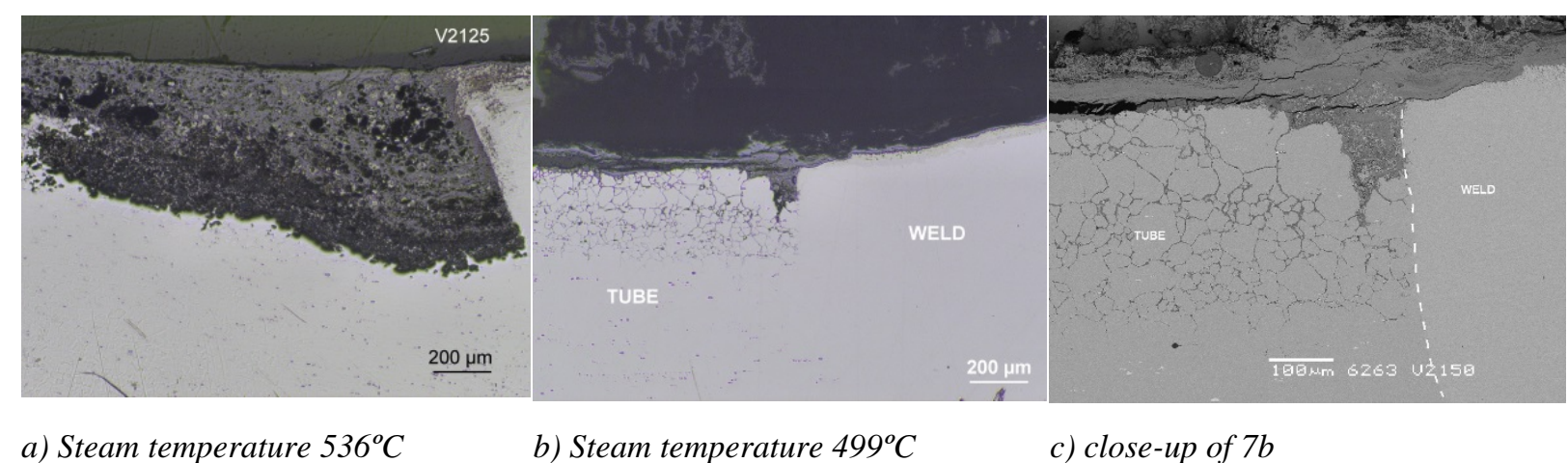

Figure 7: Weld-tube section from superheater in plant B showing effect of temperature. 


\section{TABLES:}

Table 1. Compositions for materials investigated in wt.\%.

\begin{tabular}{lllllllll}
\hline & $\mathrm{Cr}$ & $\mathrm{Fe}$ & $\mathrm{Ni}$ & $\mathrm{Mn}$ & $\mathrm{Nb}$ & $\mathrm{Si}$ & $\mathrm{C}$ & $\begin{array}{l}\text { Other } \\
\text { elements }\end{array}$ \\
\hline Plant A weld (CN 18/11 IG) $^{\mathrm{a}}$ & 18.8 & rest & 9.8 & 1.4 & & 0.6 & 0.04 & \\
Plant B weld $^{\mathrm{b}}$ & 21 & 12 & 61 & 3 & 3 & $<0,5$ & & $\mathrm{Ti}$ \\
Tube TP347H $_{\text {Nibas }^{1}}^{17.0-20.0}$ & rest & $9.0-13.0$ & 2 & 1 & $<1,0$ & $0.04-0.10$ & \\
\hline
\end{tabular}

${ }^{\mathrm{a}}$ Wire analysis, ${ }^{\mathrm{b}}$ EDS analysis

Table 2. Comparison of plant data for welds investigated

\begin{tabular}{lcccc}
\hline & Filler material & $\begin{array}{c}\text { Corrosion rate of tubes } \\
\mathbf{( m m} / \mathbf{1 0 0 0 h})\end{array}$ & $\begin{array}{c}\text { Exposure time } \\
\text { (hours) }\end{array}$ & $\begin{array}{c}\text { Estimated steam } \\
\text { temperature }\left({ }^{\circ} \mathbf{C}\right)\end{array}$ \\
\hline Plant A & CN 18/11 IG & $0.10-0.15$ & 17000 & 554 \\
Plant B & Ni rich weld & Approx. 0.05 & 30000 & 536,499 \\
\hline
\end{tabular}

Table 3. Melting points of various metal chlorides [24]

\begin{tabular}{cc}
\hline Chlorides & Melting point, ${ }^{\mathbf{0}} \mathbf{C}$ \\
\hline $\mathrm{FeCl}_{2}$ & 676 \\
$\mathrm{FeCl}_{3}$ & 303 \\
$\mathrm{NiCl}_{2}$ & 1030 \\
$\mathrm{CrCl}_{2}$ & 820 \\
$\mathrm{CrCl}_{3}$ & 1150 \\
$\mathrm{MnCl}_{2}$ & 652 \\
\hline
\end{tabular}




\begin{tabular}{lcccccccccc}
\hline Figure 3c & $\mathbf{O}$ & Si & S & Cl & K & Cr & Mn & Fe & Ni & Nb \\
\hline A & 2 & & & 25 & 28 & 5 & 1 & 32 & 7 & \\
B & 41 & & 1 & 1 & 3 & 6 & 1 & 37 & 9 & \\
C & 26 & $<1$ & $<1$ & 2 & 2 & 26 & 1 & 35 & 6 & 1 \\
D & 32 & $<1$ & $<1$ & 2 & 3 & 16 & 1 & 35 & 11 & \\
E & 2 & & $<1$ & 25 & 49 & 7 & 1 & 15 & 1 & \\
F & 18 & & $<1$ & 22 & 22 & 3 & 1 & 29 & 5 & \\
\hline
\end{tabular}

Table under Figure 3c. 


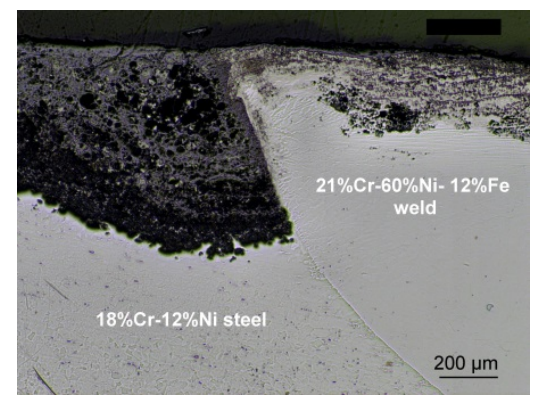

Galvanic high temperature corrosion has been observed in several plants in Denmark due to use of nickel weld materials.

This can be avoided by the use of filler materials with a matching composition to the tube.

Molten salts from the deposit and corrosion products form an electrolyte resulting in galvanic corrosion. 